\title{
Performace of triglyceride-glucose index on diagnosis and staging of NAFLD in obese patients
}

\author{
Carla Alessandra SMIDERLE ${ }^{1}$, Gabriela Perdomo CORAL ${ }^{1,2}$, Luiz Alberto DE CARLI ${ }^{3}$, \\ Angelo Alves de MATTOS $^{1,2}$, Angelo Zambam de MATTOS $^{1,2}$ and Cristiane Valle TOV0 ${ }^{1,2}$
}

Received: 06 June 2020 Accepted: 15 November 2020

\begin{abstract}
Background - Non-alcoholic fatty liver disease (NAFLD) is the most prevalent liver disease in the world, and its prevalence is increasing alongside obesity. In United States, NAFLD is already the second leading cause of liver transplantation. The spectrum of the disease ranges from simple steatosis, which has a benign course, to steatohepatitis, which may progress to cirrhosis and its complications. The rising of noninvasive methods for diagnosing and staging non-alcoholic steatohepatitis (NASH) and fibrosis decreases the need of liver biopsy, as well as the costs and the occurrence of complications related to it. Objective - To analyze the performance of the triglyceride-glucose index to evaluate steatosis, NASH and liver fibrosis in obese patients with NAFLD. Methods - This is a retrospective cross-sectional study. Every medical record of patients who were candidates for bariatric surgery at a leading hospital in Southern Brazil were analyzed. The triglyceride-glucose index (TyG Index), a method composed only of two simple laboratory tests (serum triglycerides and fasting glucose levels), was performed prior to surgery. The TyG Index performance regarding the anatomopathological findings was evaluated, and the AUROC curve was calculated to evaluate the best cut-off point for diagnosing steatosis, non-alcoholic steatohepatitis and liver fibrosis grade. Also, the NAFLD fibrosis Score (NFS) was evaluated. Results - A total of 423 patients were evaluated. The TyG Index with a cut-off point of 8.76 excluded significant simple steatosis (grade 2-3) in obese patients, with $67.6 \%$ sensitivity, $65.1 \%$ specificity, $46.3 \%$ positive predictive value (PPV), $81.8 \%$ negative predictive value (NPV), $65.8 \%$ accuracy and 0.66 AUROC ( $P=0.005)$. In the evaluation of NASH, the TyG Index with a cut-off point of 8.82 excluded significant NASH (grade 2-3) with 57.3\% sensitivity, 58.6\% specificity, 33.7\% PPV, 78.8\% NPV, 58.2\% accuracy and 0.58 AUROC $(P=0.022)$. When evaluating liver fibrosis, the TyG Index with a cut-off point of 8.91 showed a sensitivity of $61.8 \%$, a specificity of $62.5 \%$, a PPV of 13.8 and a NPV of $94.4 \%$ for exclusion of advanced fibrosis (F3-4), with a $62.4 \%$ accuracy and 0.69 AUROC $(P<0.001)$. When analyzing the performance of NFS in the diagnosis of advanced fibrosis, the cut-off point $<-1.455$ excluded advanced fibrosis with sensitivity of $59.4 \%$, specificity of $51 \%$, PPV of $11 \%$, NPV of $92.4 \%$ and accuracy of $51.7 \%$. However, the cut-off point of 0.676 to diagnose advanced fibrosis presented sensitivity of $21.9 \%$, specificity of $83 \%$, PPV of $11.7 \%$, NPV of $91.2 \%$ and $77.3 \%$ accuracy. The AUROC was $0.54(P=0.480)$. Conclusion - TyG Index did not perform well in the diagnosis of significant steatosis and NASH. However, it was able to exclude advanced fibrosis in obese patients who are candidates for bariatric surgery.
\end{abstract}

Keywords - Obesity; nonalcoholic fatty liver disease; nonalcoholic steatohepatitis; bariatric surgery; NAFLD; fatty liver.

\section{INTRODUCTION}

Non-alcoholic fatty liver disease (NAFLD) is the most prevalent liver disease in the world. The spectrum of the disease ranges from simple steatosis, which has a benign course, to steatohepatitis, which may progress to cirrhosis and its complications ${ }^{(1)}$.

The incidence of NAFLD varies from 28/1.000 person-years in the West to 52/1.000 person-years in Asia. The global prevalence of NAFLD, when diagnosed by imaging, is around $25 \%$, reaching $31.79 \%$ in the Middle East, $30.45 \%$ in South America and $13.48 \%$ in Africa. The association between NAFLD and metabolic syndrome, obesity, dyslipidemia, and type 2 diabetes mellitus (T2DM) is well established. Up to two thirds of T2DM patients are estimated to have NAFLD ${ }^{(1-4)}$.
Alongside with the growth of obesity worldwide, the incidence of NAFLD has also increased. In Southern Brazil, when the prevalence of NAFLD in obese patients is evaluated, the presence of hepatic steatosis reaches up to $90.4 \%$ and of non-alcoholic steatohepatitis (NASH) up to $70.4 \%$. In the US, about $29.9 \%$ of NAFLD patients develop NASH, currently considered the second leading cause of liver transplantation in the US and the first amongst American women. However, the leading cause of death amongst these patients is cardiovascular disease, regardless of the presence of metabolic comorbidities ${ }^{(5-9)}$.

Steatosis identification usually occurs through imaging methods. However, these methods do not distinguish steatosis from NASH, being the diagnosis of NASH still mostly dependent of liver biopsy $y^{(3)}$.

Declared conflict of interest of all authors: none

Disclosure of funding: no funding received

Research performed at: Department of Gastroenterology and Hepatology of Santa Casa de Misericórdia de Porto Alegre.

Universidade Federal de Ciências da Saúde de Porto Alegre (UFCSPA), Programa de Pós-Graduação em Hepatologia, Porto Alegre, RS, Brasil. ${ }^{2}$ Universidade Federal de Ciências da Saúde de Porto Alegre (UFCSPA), Departamento de Gastroenterologia e Hepatologia, Porto Alegre, RS, Brasil. ${ }^{3}$ Santa Casa de Misericórdia de Porto Alegre, Departamento de Cirurgia Gastrointestinal, Porto Alegre, RS, Brasil.

Corresponding author: Cristiane Valle Tovo, MD, PhD. E-mail: cristianev@ufcspa.edu.br 
In NASH there may be progression and development of liver fibrosis and cirrhosis. Therefore, it is very important to detect patients who develop NASH and, amongst them, those who develop fibrosis. Currently, liver biopsy is mostly recommended for patients with metabolic syndrome or suspected advanced fibrosis ${ }^{(3)}$.

For noninvasive assessment of the fibrosis degree, several scores have already been evaluated, amongst them FIB-4, APRI and NAFLD Fibrosis Score (NFS) are the most used. Although they present low sensitivity in detecting advanced fibrosis and are unable to assess intermediate degrees of fibrosis, they can still be of great help in preventing liver biopsy ${ }^{(10-12)}$.

However, none of the already mentioned methods are useful in identifying NASH in these patients. Considering the close association between insulin resistance and the pathophysiology of NAFLD, the TyG Index has been recommended for the diagnosis and staging of NAFLD. TyG Index is a method used to identify insulin resistance and, because it consists of only two simple laboratory tests (triglycerides and fasting glucose), its application shows some advantages ${ }^{(6,13,14)}$

The present study aims to analyze the performance of TyG Index in the evaluation of steatosis, NASH and hepatic fibrosis in morbidly obese patients diagnosed with NAFLD, who are also candidates for bariatric surgery.

\section{METHODS}

This is a cross-sectional study. All the medical records of patients who had undergone bariatric surgery between 2007 and 2016 at the Obese Treatment Center of Santa Casa de Misericórdia de Porto Alegre, a tertiary leading hospital in Southern Brazil were reviewed. Patients older than 18 years, who underwent bariatric surgery and performed intraoperative liver biopsy, and who had all laboratory data for calculating the TyG Index were included.

Patients with alcohol abuse (alcohol intake higher than 21 alcohol units/week for men and 14 alcohol units/week for women ${ }^{(3)}$ ), patients with other chronic liver diseases, using potentially steatotic medications or without this information in the medical record were excluded.

Liver biopsies were analyzed by a single pathologist experienced in hepatology according to the criteria of Kleiner et al. ${ }^{(15)}$. Simple steatosis was classified as grade 0 (absent; $<5 \%$ ), grade 1 (mild; $5 \%$ to $33 \%$ ), grade 2 (moderate; $>33 \%$ to $66 \%$ ), or grade 3 (advanced; $>66 \%$ ). The presence of NASH was diagnosed according to the NAFLD Activity Score and classified as: grade 0 (absent), grade 1 (mild), grade 2 (moderate) or grade 3 (advanced). The degree of hepatic fibrosis was classified as: F0 (absent), F1 (sinusoidal or portal / periportal fibrosis), F2 (peri-sinusoidal and portal/periportal), F3 (bridging fibrosis) and F4 (cirrhosis).

The level of triglycerides, total cholesterol (TC), low density lipoproteins (LDL), high density lipoproteins (HDL), fasting glucose, glycated hemoglobin (HbAlc), alanine aminotransferase (ALT), aspartate aminotransferase (AST), alkaline phosphatase (AP), gamma glutamyl transferase (GGT), bilirubin, platelets, albumin and prothrombin time (PT), body mass index (BMI) and the occurrence of high blood pressure and T2DM were evaluated. All the blood tests were performed within 6 months before bariatric surgery.

Two non-invasive scores were analysed: TyG Index and NAFLD Fibrosis Score.

TyG Index was calculated using the equation Ln [fasting triglycerides $(\mathrm{mg} / \mathrm{dL}) \mathrm{x}$ fasting glucose $(\mathrm{mg} / \mathrm{dL}) / 2]$, expressed on the logarithmic scale ${ }^{(16)}$.
To evaluate the performance of the TyG Index, the patients were divided into groups according to the anatomopathological findings of steatosis, NASH and liver fibrosis. Each group was further subdivided into: non-significant (grade $0-1$ ) and significant steatosis (grade 2-3); Non-significant (grade 0-1) and significant NASH (grade 2-3); non-significant (F0-2) and advanced fibrosis (F3-4). The best cut-off points for the diagnosis of significant steatosis (grade 2-3), significant NASH (grade 2-3) and advanced fibrosis (F3-4) were calculated through the area under receiver operating characteristic curve (AUROC) with its respective $95 \%$ confidence interval $(95 \% \mathrm{CI})$. Afterwards, patients where subdivided according to the presence of $\mathrm{DM}$, and the same analysis where performed for these.

The NAFLD Fibrosis Score was calculated using the equation $\mathrm{NFS}=-1.675+0.037 \mathrm{x}$ age $($ years $)+0.094 \mathrm{x}$ BMI $\left(\mathrm{kg} / \mathrm{m}^{2}\right)+1.13$ $\mathrm{x}$ IFG/diabetes (yes $=1$, no $=0)+0.99 \times$ AST/ALT ratio $-0.013 \times$ platelet $\left(\mathrm{x} 10^{9} / \mathrm{l}\right)-0.66 \times$ albumin $(\mathrm{g} / \mathrm{dL})^{(11)}$.

To evaluate the performance of the NFS, patients were divided in two groups according to the anatomopathological findings of liver fibrosis: non-significant ( $\mathrm{F} 0-2)$ and advanced fibrosis (F3-4). The cut-off points already validated in literature were applied: -1.455 to exclude advanced fibrosis and $>0.676$ to diagnose advanced fibrosis. The accuracy was calculated through the AUROC with its respective $95 \% \mathrm{CI}$.

Continuous and normal distribution variables were described as mean and standard deviation, and asymmetric variables as median and interquartile range. Categorical variables were analyzed by Student's $t$-test and ANOVA. Analyzes with $P<0.05$ were considered statistically significant. The study was submitted and approved by the institution's ethics committee (number 982.654), and written informed consent was not necessary due to the retrospective feature of this study.

\section{RESULTS}

A total of 423 medical records were reviewed in the study. The average age was $37.1 \pm 9.7$ years old, $90(21.3 \%)$ men and $333(78.7 \%)$ women, with a mean BMI of $43.8 \pm 5.6 \mathrm{~kg} / \mathrm{m}^{2}$. Amongst those, 73 $(17.3 \%)$ patients presented T2DM and $167(39.5 \%)$ hypertension.

The patients' demographic and clinical characteristics, as well as the laboratory tests can be found in TABLE 1 .

\section{Steatosis evaluation}

Forty $(9.5 \%)$ patients showed no steatosis on liver biopsy, and another $383(90.5 \%)$ had steatosis. Out of these, $80(18.9 \%)$ patients presented simple steatosis at any grade (TABLE 2).

When analyzing the performance of the TyG Index for the diagnosis of significant simple steatosis (grades 2-3), patients with NASH or liver fibrosis were not included. The best cut-off point obtained was 8.76 with $67.6 \%$ sensitivity, $65.1 \%$ specificity, positive predictive value (PPV) of $46.3 \%$, negative predictive value (NPV) of $81.8 \%$, accuracy of $65.8 \%$ and AUROC of $0.66(P 0.005)$ (TABLE 3).

When patients with T2DM were evaluated $(n=13)$, a cut-off point of 9.10 was obtained, with sensitivity of $75.0 \%$, specificity of $77.8 \%$, PPV of $60.0 \%$, NPV of $87.5 \%$, accuracy of $76.9 \%$ and AUROC of $0.61(P=0.537)$ (TABLE 4).

When evaluating patients without T2DM $(n=107)$, the best cut-off point obtained was 8.75 , with $66.7 \%$ sensitivity, $67.6 \%$ specificity, $47.8 \% \mathrm{PPV}, 82 \% \mathrm{NPV}$, accuracy of $67.3 \%$ and AUROC of 0.68 ( $P$ 0.003) (TABLE 5). 
TABLE 1 Demographic, clinical and laboratory features of analyzed patients.

\begin{tabular}{|c|c|}
\hline Variables & $\mathrm{n}=423$ \\
\hline Age (years) - mean $\pm \mathrm{SD}$ & $37.1 \pm 9.7$ \\
\hline Female- n $(\%)$ & $333(78.7)$ \\
\hline $\mathrm{BMI}\left(\mathrm{kg} / \mathrm{m}^{2}\right)-$ mean $\pm \mathrm{SD}$ & $43.8 \pm 5.6$ \\
\hline $\mathrm{T} 2 \mathrm{DM}-\mathrm{n}(\%)$ & $73(17.3)$ \\
\hline $\mathrm{HBP}-\mathrm{n}(\%)$ & $167(39.5)$ \\
\hline Glycemia $(\mathrm{mg} / \mathrm{dL})-$ mean $\pm \mathrm{SD}$ & $101.3 \pm 33.6$ \\
\hline $\mathrm{HbA} 1 \mathrm{c}(\%)-$ mean $\pm \mathrm{SD}$ & $5.88 \pm 1.31$ \\
\hline Trigliceryde $(\mathrm{mg} / \mathrm{dL})-$ median $(\mathrm{P} 25-\mathrm{P} 75)$ & $137(98-189)$ \\
\hline $\mathrm{TC}(\mathrm{mg} / \mathrm{dL})-$ mean $\pm \mathrm{SD}$ & $196.2 \pm 39.3$ \\
\hline $\mathrm{LDL}(\mathrm{mg} / \mathrm{dL})-$ mean $\pm \mathrm{SD}$ & $116.5 \pm 33.2$ \\
\hline $\mathrm{HDL}(\mathrm{mg} / \mathrm{dL})-$ mean $\pm \mathrm{SD}$ & $48.4 \pm 12.4$ \\
\hline Albumin $(\mathrm{g} / \mathrm{dL})-$ mean $\pm \mathrm{SD}$ & $4.26 \pm 0.29$ \\
\hline Bilirubin $(\mathrm{mg} / \mathrm{dL})-$ mean $\pm \mathrm{SD}$ & $0.52 \pm 0.25$ \\
\hline $\mathrm{AP}(\mathrm{U} / \mathrm{L})-$ mean $\pm \mathrm{SD}$ & $86.9 \pm 38.6$ \\
\hline GGT $(\mathrm{U} / \mathrm{L})-\operatorname{median}(\mathrm{P} 25-\mathrm{P} 75)$ & $34(24-47)$ \\
\hline $\operatorname{AST}(\mathrm{U} / \mathrm{L})-$ mean $\pm \mathrm{SD}$ & $26.5 \pm 12.7$ \\
\hline $\operatorname{ALT}(\mathrm{U} / \mathrm{L})-$ mean $\pm \mathrm{SD}$ & $34.1 \pm 21.6$ \\
\hline Platelets $\left(/ \mathrm{uL} 10^{9}\right)-$ mean $\pm \mathrm{SD}$ & $285.2 \pm 69.7$ \\
\hline $\mathrm{PT}(\%)-$ mean $\pm \mathrm{SD}$ & $95.4 \pm 6.87$ \\
\hline
\end{tabular}

TABLE 2. Staging according to anatomopathologycal features.

\begin{tabular}{cc}
\hline Anatomopathology & N (\%) \\
\hline Simple steatosis & $80(100)$ \\
Grade 1 - Mild & $43(53.8)$ \\
Grade 2 - Moderate & $18(22.5)$ \\
Grade 3 - Advanced & $19(23.7)$ \\
NASH & $303(100)$ \\
Grade 1 - Mild & $200(66.0)$ \\
Grade 2 - Moderate & $103(34.0)$ \\
Grade 3 - Advanced & $0(0)$ \\
Fibrosis & $221(100)$ \\
F1 & $172(77.8)$ \\
F2 & $15(6.8)$ \\
F3 & $33(14.9)$ \\
F4 & $1(0.5)$ \\
\hline
\end{tabular}

\section{NASH evaluation}

In the evaluation of NASH ( $\mathrm{n}=303), 200(66 \%)$ had pathological examination compatible with mild NASH and $103(34 \%)$ with moderate NASH. No advanced NASH was identified (TABLE 2).

When analyzing the performance of the TyG Index for significant NASH diagnosis (grade 2-3), all 383 patients with steatosis were considered. The best cut-off point achieved was 8.82 with $57.3 \%$ sensitivity, $58.6 \%$ specificity, PPV of $33.7 \%$, NPV of $78.8 \%$, accuracy of $58.2 \%$ and AUROC of 0.58 ( $P=0.022)$ (TABLE 3$)$.

When patients with T2DM $(n=68)$ were evaluated, a cut-off point of 9.34 was obtained, with sensitivity of $53.6 \%$, specificity of $52.5 \%$, PPV of $44.1 \%$, NPV of $61.8 \%$, accuracy of $52.9 \%$ and AUROC of $0.61(P=0.122)$ (TABLE 4).

When patients without T2DM $(\mathrm{n}=315)$ were evaluated, the cutoff point was 8.73 , with sensitivity of $52.0 \%$, specificity of $52.5 \%$, PPV of $25.5 \%$, NPV of $77.8 \%, 52.4 \%$ accuracy and 0.52 AUROC $(P=0.664)$ (TABLE 5).

\section{Liver fibrosis assessment}

Amongst all the patients analyzed, 221 (52.2\%) showed some grade of fibrosis on the liver biopsy. Out of these, $172(77.8 \%)$ had $\mathrm{F} 1,15(6.8 \%) \mathrm{F} 2$ and $33(14,9 \%) \mathrm{F} 3$. Only $1(0.5 \%)$ patient presented with cirrhosis (F4) (TABLE 2).

When analyzed the performance of TyG Index in the diagnosis of advanced fibrosis (F3-4), all 383 patients with steatosis were considered. The best cut-off point obtained was 8.91 with sensitivity of $61.8 \%$, specificity of $62.5 \%$, PPV of $13.8 \%, 94.4 \%$ NPV, $62.4 \%$ accuracy and 0.69 AUROC $(P<0.001)$ (TABLE 3).

In the exclusive evaluation of patients with T2DM, the cut-off point reached was 9.40 , with sensitivity of $61.1 \%$, specificity of $58 \%$, PPV of $34.4 \%$, NPV of $80.6 \%$, accuracy of $58.8 \%$ and AUROC of $0.66(P=0.044)$ (TABLE 4$)$.

When only patients without T2DM were evaluated, the cutoff point achieved was 8.80 , with sensitivity of $62.5 \%$, specificity of $59.2 \%$, PPV of $7.6 \%$, NPV of $96.7 \%$, accuracy of $59.4 \%$ and AUROC of $0.57(P=0.376)$ (TABLE 5).

When analyzing the performance of NFS in the diagnosis of advanced fibrosis, the lower cut-off point of $<-1.455$ to exclude advanced fibrosis presented a sensitivity of $59.4 \%$, specificity of $51 \%$, PPV of $11 \%$, NPV of $92.4 \%$ and accuracy of $51.7 \%$. However, the higher cut-off point of 0.676 to diagnose advanced fibrosis presented a sensitivity of $21.9 \%$, specificity of $83 \%$, PPV of $11.7 \%$, NPV of $91.2 \%$ and $77.3 \%$ accuracy. The AUROC was $0.54(P=0.480)($ FIGURE 1).

TABLE 3. Performance evaluation of TyG Index in obese patients.

\begin{tabular}{lcccccccc}
\hline & $\mathbf{n}$ & Cut-off point & Sen & Spe & PPV & NPV & AUC (95\% CI) & $P$ \\
\hline Simple Steatosis (0-1 x 2-3) & 120 & 8.76 & 67.6 & 65.1 & 46.3 & 81.8 & $0.66(0.66-0.77)$ & 0.005 \\
NASH (0-1 x 2-3) & 383 & 8.82 & 57.3 & 58.6 & 33.7 & 78.8 & $0.58(0.51-0.64)$ & 0.022 \\
Fibrosis (0-2 x 3-4) & 383 & 8.91 & 61.8 & 62.5 & 13.8 & 94.4 & $0.69(0.60-0.78)$ & $<0.001$ \\
\hline
\end{tabular}

Sen: sensibility, Spe: specificity. PPV: positive predictive value; NPV: negative predictive value; AUC: area under the curve; NASH: non-alcoholic steatohepatitis.

TABLE 4. Performance evaluation of TyG Index in obese patients with T2DM.

\begin{tabular}{lcccccccc}
\hline & $\mathbf{n}$ & Cut-off point & Sen & Spe & PPV & NPV & AUC (95\% CI) & P \\
\hline SimpleSteatosis (0-1 x 2-3) & 13 & 9.10 & 75.0 & 77.8 & 60.0 & 87.5 & $0.61(0.22-1.00)$ & 0.537 \\
NASH (0-1 x 2-3) & 68 & 9.34 & 53.6 & 52.5 & 44.1 & 61.8 & $0.61(0.48-0.75)$ & 0.122 \\
Fibrosis (0-2 x 3-4) & 68 & 9.40 & 61.1 & 58 & 34.4 & 80.6 & $0.66(0.52-0.81)$ & 0.044 \\
\hline
\end{tabular}

Sen: sensibility, Spe: specificity. PPV: positive predictive value; NPV: negative predictive value; AUC: area under the curve; NASH: non-alcoholic steatohepatitis. 
TABLE 5. Performance evaluation of TyG Index in obese patients without T2DM

\begin{tabular}{lcccccccc}
\hline & n & Cut-off point & Sen & Spe & PPV & NPV & AUC (95\% CI) & $\boldsymbol{P}$ \\
\hline Simple Steatosis (0-1 x 2-3) & 107 & 8.75 & 66.7 & 67.6 & 47.8 & 82.0 & $0.68(0.57-0.79)$ & 0.003 \\
NASH (0-1 x 2-3) & 315 & 8.73 & 52.0 & 52.5 & 25.5 & 77.8 & $0.52(0.44-0.59)$ & 0.664 \\
Fibrosis (0-2 x 3-4) & 315 & 8.80 & 62.5 & 59.2 & 7.6 & 96.7 & $0.57(0.44-0.69)$ & 0.376 \\
\hline
\end{tabular}

Sen: sensibility, Spe: specificity. PPV: positive predictive value; NPV: negative predictive value; AUC: area under the curve; NASH: non-alcoholic steatohepatitis.

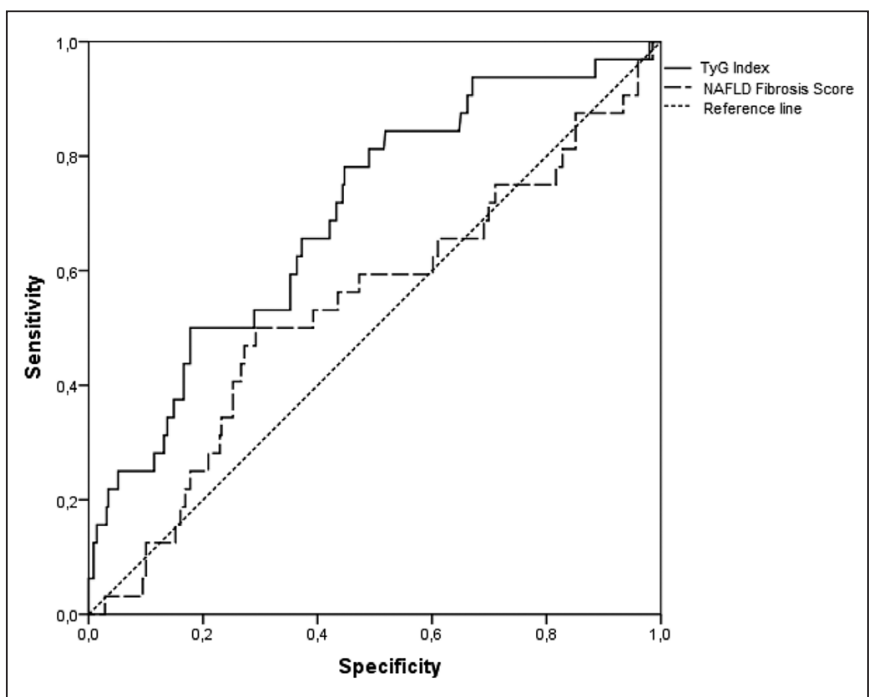

FIGURE 1. AUROC for identification of advanced fibrosis from TyG Index and NAFLD Fibrosis Score in relation to liver biopsy. TyG Index: AUROC 0.69 (95\%CI: 0.6-0.78); $P<0.001$

NAFLD Fibrosis Score: AUROC 0.54 (95\%CI: 0.43-0.65); $P=0.480$.

\section{DISCUSSION}

The interest in NAFLD diagnosis and staging has been growing exponentially. Several methods have been proposed for noninvasive evaluation, not always presenting a satisfactory performance ${ }^{(6,11-13)}$.

In the present study, when evaluating morbidly obese candidates for bariatric surgery, steatosis was observed in $90.5 \%$ of them, NASH in $71.6 \%$ and some degree of fibrosis in $52.2 \%$ of patients. These results are similar to other authors, which has presented a prevalence of steatosis from $61.2 \%$ to $86 \%$ and NASH from $30.9 \%$ to $77.5 \%$ amongst patients who are candidates for bariatric surgery ${ }^{(17-19)}$.

The present study evaluated a new noninvasive score (TyG Index) for diagnosis and staging of NAFLD, which showed modest performance in excluding significant simple steatosis and NASH, regardless of the presence of T2DM.

Regarding the degree of liver fibrosis, the TyG Index was able to assist in the exclusion of patients with advanced fibrosis, especially in the population without T2DM.

Few studies have previously analyzed the TyG Index in NAFLD. A Chinese cohort study by Zheng et al. ${ }^{(20)}$ suggested the TyG Index as an independent predictor for the diagnosis of hepatic steatosis. The evaluated population consisted of 4.539 workers followed up from 2006-2015, and the development of steatosis was assessed by abdominal ultrasound. The ideal cut-off point for steatosis prediction was 8.52 , with $67 \%$ sensitivity, $71.9 \%$ specificity and 0.76 AUROC $(95 \%$ CI $0.74-0.77)$. The mean BMI of the evaluated population was $23.9 \mathrm{~kg} / \mathrm{m}^{2}$ in those with steatosis and $21.5 \mathrm{~kg} / \mathrm{m}^{2}$ in those without steatosis. Another Chinese ${ }^{(21)}$ retrospective study, compared TyG Index's performance to abdominal ultrasound for steatosis detection in 10.761 workers, obtaining the best cut-off point of 8.5 , with sensitivity of $72.2 \%$, specificity of $70.5 \%$ and AUROC of 0.78 (95\%CI $0.77-0.79)$, and it also showed better performance in the diagnosis of steatosis in non-obese individuals. However, it is important to emphasize that in this study patients with $\mathrm{BMI}>25 \mathrm{~kg} / \mathrm{m}^{2}$ were considered obese.

In Mexico, Simental-Medía et al. ${ }^{(13)}$ used the TyG Index as a noninvasive diagnostic tool for NAFLD in 50 asymptomatic women with a mean BMI of $33 \pm 7.1 \mathrm{~kg} / \mathrm{m}^{2}$ submitted to liver biopsy, and compared it to anatomopathological findings. In this cross-sectional study, cut-off points were obtained well below those found in the present study, with 4.58 (94\% sensitivity and $69 \%$ specificity) for steatosis diagnosis, which outperformed NFS, SteatoTest, NashTest and Fatty Liver Index. The small number of patients evaluated and the absence of male patients restrain the legitimacy of the study.

In the present study, the cut-off point adopted was 8.76, but, despite the optimistic proposal of Zheng et al. ${ }^{(20)}$ and Zhang et al. ${ }^{(21)}$, we believe that the accuracy of the method is low, and thus does not serve the same purporse regarding noninvasive evaluation of this population. We highlight the fact that the patients here evaluated have a mean BMI of $43.8 \pm 5.6 \mathrm{~kg} / \mathrm{m}^{2}$.

Regarding NASH, so far there is no noninvasive method described with satisfactory performance in its identification. Simental-Medía et al. ${ }^{(13)}$ proposed the TyG Index as a tool for the diagnosis of NASH, with a cut-off point of 4.59 (sensitivity of $87 \%$ and specificity of $69 \%$ ) in asymptomatic women, with a superior performance compared to the ones obtained in the tests widely known. However, the present study demonstrated a modest TyG Index performance in the identification of significant NASH in the evaluated population, not reproducing the findings described by Simental-Medía et al. ${ }^{(13)}$.

Fedchuck et al. ${ }^{(22)}$ reported a TyG Index accuracy of $90 \%$ and a PPV of $99 \%$ in the diagnose simple steatosis $\geq 5 \%$ when using the cut-off point of 8.38. However, it was unable to differenciate the degree of liver steatosis. In relation to NASH, TyG Index did not perform well in the diagnosis and staging. Regarding fibrosis, they found a positive correlation between TyG Index and the degree of fibrosis assessed by liver biopsy, with mean cutoff value of $8.8 \pm 0.7$ for patients with fibrosis F1-2 and $9.0 \pm 0.7$ for advanced fibrosis.

In a population composed of 89 obese patients candidates to bariatric surgery evaluated by Cazzo et al. ${ }^{(23)}$, with mean BMI $37.4 \pm 2.8$, there was no statistical difference in the mean values of TyG Index amongst patients with or without simple steatosis, NASH and fibrosis. However, when assessing insuline resistance, TyG Index, HOMA-IR and TG/HDL-c mean values also did not have statistical difference amongst this groups.

In a patient population similar to the present study, also composed of individuals undergoing bariatric surgery with NAFLD, Faure et al. ${ }^{(14)}$ evaluated the performance of the TyG Index. A total of 147 patients with BMI $41 \pm 5 \mathrm{~kg} / \mathrm{m}^{2}$ were evaluated. Out of these, 30 patients had T2DM and 47 were insulin resistant (HOMA 
$\geq 3$ ). Liver biopsy identified steatosis in $66 \%$ of patients, NASH in $11 \%$ and fibrosis in $24 \%$. This study identified the TyG Index as a predictor of NASH $(P<0.0001)$, liver fibrosis in any degree $(<0.01)$ and F3-4 liver fibrosis $(P<0.05)$ in these patients. However, to date the study has not yet been fully published and data regarding performance is not available.

In the present study, when the TyG Index was evaluated to identify advanced fibrosis, despite AUROC being 0.69 presented a high NPV (94.4\%), which could avoid liver biopsy in a significant number of patients.

Other non-invasive surrogate markers had been studied to evaluate the presence of advanced fibrosis in patients with NAFLD. The NFS was developed specifically for these patients and, on its validation study, it could have avoided up to $75 \%$ of liver biopsies ${ }^{(11)}$. However, it has a modest performance in obese patients ${ }^{(24,25)}$. Regarding the evaluation of advanced fibrosis using NFS in the present study, it did not perform satisfactorily. Despite its high NPV to exclude and to diagnose advanced fibrosis $(92.4 \%$ and $91.2 \%$ respectively), its AUROC was 0.54 (95\%IC: $0.43-0.65$ ), being even lower than the AUROC observed with the TyG Index (0.69; 95\% CI: 0.6-0.78).

Some biomarkers designed for other populations have their use extrapolated to NAFLD patients, such as APRI and FIB-4 ${ }^{(25,26)}$. De Cleva et al. ${ }^{(26)}$ found APRI to be the best predictor of advanced liver fibrosis in obese patients amongst several non-invasive markers. However, this study did not evaluate the NFS.

In the present study, APRI and FIB-4 were not evaluated because of the asymmetrical distribution of the patients, making it impossible to carry out the statistical analysis. The limitations of the present study are its retrospective nature, the absence of patients with advanced NASH and the small number of patients with F4 fibrosis. On the other hand, the number of patients evaluated was significant, and all of them underwent liver biopsy, which is still considered the gold standard for diagnosis and has not always been used in other studies.

In conclusion, the TyG Index did not perform well for the diagnosis of significant NASH in the evaluated population. However, it was able to exclude advanced fibrosis in obese patients who are candidates for bariatric surgery, hence further prospective studies are needed in order to validate these findings. Also, the development of an application to facilitate the calculation would be of great help for physicians to use TyG Index for assessing liver fibrosis on clinical care

\section{Authors' contribution}

Smiderle CA manuscript writing, drafting conception, design and data analysis. Coral GP pathology analysis. De Carli LA performing procedures and patient care. Mattos AA critical review of the manuscript. Mattos AZ critical review of the manuscript. Tovo CV final approval of the version of the article to be published.

\section{Orcid}

Carla Alessandra Smiderle: 0000-0002-2873-7069.

Gabriela Perdomo Coral: 0000-0003-4318-2871.

Luiz Alberto De Carli: 0000-0001-8875-9908.

Angelo Alves de Mattos: 0000-0003-2417-9765.

Angelo Zambam de Mattos: 0000-0002-3063-0199.

Cristiane Valle Tovo: 0000-0002-7932-5937.

Smiderle CA, Coral GP, De Carli LA, Mattos AA, Mattos AZ, Tovo CV. Avaliação do desempenho do índice triglicerídeo-glicose no diagnóstico e estadiamento da DHGNA em pacientes obesos. Arq Gastroenterol. 2021;58(2):139-44.

RESUMO - Contexto - A doença hepática gordurosa não-alcoólica (DHGNA) é a doença hepática mais prevalente no mundo. Nos Estados Unidos, a DHGNA já é a segunda causa de transplante hepático. O espectro da doença abrange desde a esteatose simples, que apresenta curso benigno, até esteato-hepatite não-alcoólica (EHNA), que pode progredir para cirrose e suas complicações. O desenvolvimento de métodos não invasivos para o diagnóstico e estadiamento da EHNA e da fibrose hepática visa diminuir a necessidade de biópsia hepática, um procedimento invasivo e não raro associado a complicações. Objetivo - Analisar o desempenho do índice triglicerídeo-glicose (TyG Index) para o diagnóstico e estadiamento da DHGNA em pacientes obesos. Métodos - Este é um estudo transversal retrospectivo. Foram analisados todos os prontuários de pacientes candidatos a cirurgia bariátrica em um hospital de referência do Sul do Brasil e calculado o TyG Index, um escore composto por dois exames laboratoriais (triglicerídeos e glicose de jejum), realizados previamente à cirurgia. O desempenho do TyG Index em relação aos achados anatomopatológicos hepáticos foi avaliado, e calculada a curva ROC para avaliação de esteatose simples, EHNA e fibrose hepática. O NAFLD Fibrosis Score (NFS) também foi avaliado. Resultados - Foram avaliados 423 pacientes. O melhor ponto de corte do TyG Index para a exclusão de esteatose simples significativa (grau 2-3) foi de 8,76 , com sensibilidade $67,6 \%$, especificidade $65,1 \%$, valor preditivo positivo (VPP) $46,3 \%$, valor preditivo negativo (VPN) $81,8 \%$, acurácia $65,8 \%$ e AUROC 0,66 ( $P=0,005)$. Na avaliação de EHNA significativa (grau 2-3), o melhor ponto de corte foi de 8,82 com sensibilidade 57,3\%, especificidade $58,6 \%$, VPP $33,7 \%$, VPN 78,8\%, acurácia 58,8\% e AUROC $0,58(P=0,022)$. Em relação à fibrose avançada (grau 3-4), o melhor ponto de corte do TyG Index foi de 8,91 com sensibilidade 61,8\%, especificidade 62,5\%, VPP 13,8\%, VPN 94,4\%, acurácia 62,4\% e AUROC 0,69 (P<0,001). Ao analisarmos o desempenho do NFS no diagnóstico de fibrose avançada, o ponto de corte de $<-1,455$ excluiu fibrose avançada com sensibilidade $59,4 \%$, especificidade 51\%, VPP 11\%, VPN 92,4\% e acurácia 51,7\%. Entretanto, o ponto de corte de 0,676 para fibrose avançada apresentou sensibilidade de $21,9 \%$, especificidade $83 \%$, VPP $11,7 \%$, VPN 91,2\% e acurácia 77,3\%. A AUROC foi de $0,54(P=0,480)$. Conclusão - O TyG Index não apresentou bom desempenho para o diagnóstico e estadiamento da esteatose simples e da EHNA. Entretanto, foi capaz de excluir fibrose avançada em pacientes obesos candidatos a cirurgia bariátrica.

Palavras-chave - Obesidade; hepatopatia gordurosa não-alcoólica; esteato-hepatite; cirurgia bariátrica; esteatose hepática. 


\section{REFERENCES}

1. Younossi ZM, Koenig AB, Abdelatif D, Fazel Y, Henry L, Wymer M. Global epidemiology of nonalcoholic fatty liver disease-Meta-analytic assessment of prevalence, incidence, and outcomes. Hepatology. 2016;64:73-84

2. Subichin M, Clanton J, Makuszewski M, Bohon A, Zografakis JG, Dan A. Live disease in the morbidly obese: a review of 1000 consecutive patients undergoing weight loss surgery. Surg Obes Relat Dis. 2015;11:137-41.

3. Chalasani N, Younossi Z, Lavine JE, Charlton M, Cusi K, Rinella M, et al. The diagnosis and management of nonalcoholic fatty liver disease: Practice guidance from the American Association for the Study of Liver Diseases. Hepatology [Internet]. 2018;67:328-57. Available from: http://doi.wiley.com/10.1002/hep.29367

4. Younossi ZM, Golabi P, de Avila L, Paik JM, Srishord M, Fukui N, et al. The global epidemiology of NAFLD and NASH in patients with type 2 diabetes: A systematic review and meta-analysis. J Hepatol. 2019;71:793-801.

5. Williams CD, Stengel J, Asike MI, Torres DM, Shaw J, Contreras M, et al. Prevalence of Nonalcoholic Fatty Liver Disease and Nonalcoholic Steatohepatitis Among a Largely Middle-Aged Population Utilizing Ultrasound and Liver Biopsy: A Prospective Study. Gastroenterology. 2011;140:124-31.

6. Losekann A, Weston A, de Mattos A, Tovo C, de Carli L, Espindola M, et al Non-Alcoholic Steatohepatitis (NASH): Risk Factors in Morbidly Obese Patients Int J Mol Sci. [Internet]. 2015;16:25552-9. Available from: http://www.mdpi com/1422-0067/16/10/25552

7. Wong RJ, Aguilar M, Cheung R, Perumpail RB, Harrison SA, Younossi ZM, et al. Nonalcoholic Steatohepatitis Is the Second Leading Etiology of Live Disease Among Adults Awaiting Liver Transplantation in the United States. Gastroenterology. 2015;148:547-55.

8. Haflidadottir S, Jonasson JG, Norland H, Einarsdottir SO, Kleiner DE, Lund SH, et al. Long term follow-up and liver-related death rate in patients with non-alcoholic and alcoholic related fatty liver disease. BMC Gastroenterol. 2014;27:14-166.

9. Noureddin M, Vipani A, Bresee C, Todo T, Kim IK, Alkhouri N, et al. NASH Leading Cause of Liver Transplant in Women: Updated Analysis of Indications for Liver Transplant and Ethnic and Gender Variances. Am J Gastroenterol 2018;113:1649-59.

10. Kruger FC, Daniels CR, Kidd M, Swart G, Brundyn K, van Rensburg C, et al APRI: a simple bedside marker for advanced fibrosis that can avoid liver biopsy in patients with NAFLD/NASH. S Afr Med J. 2011;101:477-80.

11. Angulo P, Hui JM, Marchesini G, Bugianesi E, George J, Farrell GC, et al. The NAFLD fibrosis score: A noninvasive system that identifies liver fibrosis in patients with NAFLD. Hepatology. 2007;45:846-54

12. Shah AG, Lydecker A, Murray K, Tetri BN, Contos MJ, Sanyal AJ, et al Comparison of noninvasive markers of fibrosis in patients with nonalcoholic fatty liver disease. Clin Gastroenterol Hepatol. 2009;7:1104-12

13. Simental-Mendía LE, Simental-Mendía E, Rodríguez-Hernández H, Rodríguez-Morán M, Guerrero-Romero F. The product of triglycerides and glucose as biomarker for screening simple steatosis and NASH in asymptomatic women. Ann Hepatol. 2016;15:715-20.
14. Faure S, Benjamin R, Ramos J, Medhi S, David N, Anne L, et al. The triglycerides and glucose (TyG) index: a new marker associated with Non Alcoholic Steatohepatitis (NASH) and fibrosis in obese patients?. J Hepatol. 2018;68:S835.

15. Kleiner DE, Brunt EM, Van Natta M, Behling C, Contos MJ, Cummings OW, et al. Design and validation of a histological scoring system for nonalcoholic fatty liver disease. Hepatology. 2005;41:1313-21.

16. Simental-Mendía LE, Rodríguez-Morán M, Guerrero-Romero F. The Product of Fasting Glucose and Triglycerides As Surrogate for Identifying Insulin Resistance in Apparently Healthy Subjects. Metab Syndr Relat Disord. 2008;6:299-304.

17. Beymer C, Kowdley K V, Larson A, Edmonson P, Dellinger EP, Flum DR. Prevalence and predictors of asymptomatic liver disease in patients undergoing gastric bypass surgery. Arch Surg. 2003;138:1240-4.

18. Udelsman B V., Corey KE, Lindvall C, Gee DW, Meireles OR, Hutter MM, et al. Risk factors and prevalence of liver disease in review of 2557 routine liver biopsies performed during bariatric surgery. Surg Obes Relat Dis. 2019, 15:843-9.

19. Seki Y, Kakizaki S, Horiguchi N, Hashizume H, Tojima H, Yamazaki Y, et al. Prevalence of nonalcoholic steatohepatitis in Japanese patients with morbid obesity undergoing bariatric surgery. J Gastroenterol. 2016;51:281-9.

20. Zheng R, Du Z, Wang M, Mao Y, Mao W. A longitudinal epidemiological study on the triglyceride and glucose index and the incident nonalcoholic fatty liver disease. Lipids Health Dis. 2018;17:262

21. Zhang S, Du T, Zhang J, Lu H, Lin X, Xie J, et al. The triglyceride and glucose index (TyG) is an effective biomarker to identify nonalcoholic fatty liver disease. Lipids Health Dis. 2017;16:15.

22. Fedchuk L, Nascimbeni F, Pais R, Charlotte F, Housset C, Ratziu V. Performance and limitations of steatosis biomarkers in patients with nonalcoholic fatty liver disease. Aliment Pharmacol Ther. 2014;40:1209-22.

23. Cazzo E, Jimenez LS, Gestic MA, Utrini MP, Chaim FHM, Chaim FDM, et al. Type 2 Diabetes Mellitus and Simple Glucose Metabolism Parameters may Reliably Predict Nonalcoholic Fatty Liver Disease Features. Obes Surg. 2018:28:187-94

24. de Carli M Al, de Carli LA, Correa MB, Junqueira G, Tovo CV, Coral GP Performance of noninvasive scores for the diagnosis of advanced liver fibrosis in morbidly obese with nonalcoholic fatty liver disease. Eur J Gastroenterol Hepatol. 2020;32:420-5

25. Tovo C V., Villela-Nogueira CA, Leite NC, Panke CL, Port GZ, Fernandes S, et al Transient hepatic elastography has the best performance to evaluate liver fibrosis in non-alcoholic fatty liver disease (NAFLD). Ann Hepatol. 2019;18:445-9.

26. De Cleva R, Duarte LF, Crenitte MRF, De Oliveira CPM, Pajecki D, Santo MA. Use of noninvasive markers to predict advanced fibrosis/cirrhosis in severe obesity. Surg Obes Relat Dis [Internet]. 2016;12:862-7. Available from: http:// dx.doi.org/10.1016/j.soard.2015.11.011 